\title{
Capture of Nontarget Flies (Diptera: Lauxaniidae, Chloropidae, and Anthomyiidae) on Traps Baited with Volatile Chemicals in Field-Crop Habitats
}

\author{
Louis S. Hesler \\ North Central Agricultural Research Laboratory, USDA-ARS, Brookings, SD 57006, USA \\ Correspondence should be addressed to Louis S. Hesler; louis.hesler@ars.usda.gov
}

Received 30 April 2016; Accepted 18 July 2016

Academic Editor: G. Wilson Fernandes

Copyright (C) 2016 Louis S. Hesler. This is an open access article distributed under the Creative Commons Attribution License, which permits unrestricted use, distribution, and reproduction in any medium, provided the original work is properly cited.

Volatile chemicals increased trap catch of flies from the families Lauxaniidae [Homoneura bispina (Loew) and Camptoprosopella borealis Shewell], Chloropidae (Olcella sp.), and Anthomyiidae (Delia spp.) in field crops. With lauxaniids, baiting with 2phenylethanol on cotton-roll dispensers increased catch of $H$. bispina in two corn plot tests, and methyl salicylate increased trap catch in one test. Traps baited with methyl salicylate increased the catch of $C$. borealis. When using plastic-sachet dispensers, traps baited with methyl salicylate caught more H. bispina than ones baited with 2-phenylethanol, whereas traps baited with 2-phenylethanol caught more C. borealis than those with methyl salicylate. For chloropids, traps baited with 2-isopropyl-3methoxypyrazine greatly increased catch of Olcella flies in corn and soybean. With anthomyiids, catch of male Delia flies in wheat increased with 2-phenylethanol on cotton rolls and with either 2-phenylethanol or methyl salicylate using plastic dispensers. In soybean, 2-phenylethanol formulated on cotton rolls or in plastic dispensers increased catch of male Delia flies, but methyl salicylate did not affect trap catch. Trap catch of female Delia flies did not vary among chemicals. In another test in soybean, trap catch of both male and female Delia flies was greater with 2-phenylethanol than with other volatile chemicals.

\section{Introduction}

Chemical cues are important to the basic life history of insects in activities such as locating food, finding mates, and recognizing suitable habitat [1]. However, the chemical ecology of many insects is still poorly understood. This is particularly true for noneconomic species, as methodical studies on their chemical ecology are often lacking.

Although systematic, hypothesis-driven research can produce novel information about insect chemical ecology, new knowledge may sometimes arise from unexpected sources [2]. This is frequently the case for many flight-capable insects that are captured unwittingly in traps provisioned with volatile chemicals intended to attract one or a few target species of insects $[3,4]$. Substantial bycatch of a particular nontarget species may reveal a novel association between that species and the chemical [5-7]. Thus, this bycatch may be used to expand knowledge regarding the chemical ecology of various nontarget insects $[4,6]$.
Large bycatches of nontarget flies were sometimes unwittingly encountered in a study [8] that I conducted to evaluate responsiveness of arthropod natural enemies to various volatile chemicals among various field-crop habitats. Significant numbers of flies from three different families (Lauxaniidae, Chloropidae, and Anthomyiidae) were captured, and some captures represented potentially novel associations with volatile chemicals. The objective of this paper is to report on the associations of volatile chemicals with trap catch of the nontarget flies in my study.

\section{Materials and Methods}

Nontarget flies were captured unexpectedly on traps baited with individual volatile chemicals (Table 1; Figure 1) in seven separate field tests (Table 2) in 2004 and 2005 near Brookings, $\mathrm{SD}$. As the catch of these flies was unexpected, their response to the volatile chemicals was evaluated on an ad hoc basis 
TABLE 1: Volatile chemicals tested for attraction to beneficial insects in agricultural plots near Brookings, SD.

\begin{tabular}{|c|c|c|c|c|}
\hline Volatile chemical & & Alternate chemical name & Dosage, dispenser & \\
\hline \multicolumn{5}{|l|}{ Year 2004} \\
\hline Camphor & CAM & 1,7,7-Trimethylbicyclo[2.2.1]heptan-2-one & $100 \mathrm{mg}$, cotton roll & $\begin{array}{l}\text { Sigma-Aldrich, St. Louis, } \\
\text { MO }\end{array}$ \\
\hline $\begin{array}{l}\text { Ethanol (nonattractant } \\
\text { control) }\end{array}$ & ETH & & $100 \mathrm{mg}$, cotton roll & $\begin{array}{l}\text { Sigma-Aldrich, St. Louis, } \\
\text { MO }\end{array}$ \\
\hline $\begin{array}{l}\text { 2-Isopropyl-3- } \\
\text { methoxypyrazine }\end{array}$ & IMP & 2-Isopropyl-3-methoxypyrazine & $100 \mathrm{mg}$, cotton roll & $\begin{array}{l}\text { Sigma-Aldrich, St. Louis, } \\
\text { MO }\end{array}$ \\
\hline 2-Phenylethanol & $\mathrm{PE}$ & 2-Phenylethanol & $100 \mathrm{mg}$, cotton roll & $\begin{array}{c}\text { Sigma-Aldrich, Milwaukee, } \\
\text { WI }\end{array}$ \\
\hline Terpineol (mixed isomers) & TERP & $\begin{array}{l}\text { 2-(4-Methyl-1-cyclohex-3-enyl)propan-2- } \\
\text { ol }\end{array}$ & $100 \mathrm{mg}$, cotton roll & $\begin{array}{c}\text { Sigma-Aldrich, St. Louis, } \\
\text { MO }\end{array}$ \\
\hline trans-Caryophyllene & TC & $\begin{array}{l}\text { trans-(1R,9S)-8-Methylene-4,11,11- } \\
\text { trimethylbicyclo-undec-4-ene }\end{array}$ & $100 \mathrm{mg}$, cotton roll & $\begin{array}{l}\text { Spectrum Chemical, } \\
\text { Gardena, CA }\end{array}$ \\
\hline \multicolumn{5}{|l|}{ Year 2005} \\
\hline 4-Allylanisole & $4 \mathrm{AA}$ & 1-Methoxy-4-(2-propenyl)benzene & $100 \mathrm{mg}$, cotton roll & $\begin{array}{c}\text { Sigma-Aldrich, Milwaukee, } \\
\text { WI }\end{array}$ \\
\hline $\begin{array}{l}\text { Ethanol (nonattractant } \\
\text { control) }\end{array}$ & ETH & & $100 \mathrm{mg}$, cotton roll & $\begin{array}{c}\text { Sigma-Aldrich, St. Louis, } \\
\text { MO }\end{array}$ \\
\hline $\begin{array}{l}\text { Ethanol (nonattractant } \\
\text { control) }\end{array}$ & ETCL & & $2 \mathrm{mg}$, commercial dispenser & $\begin{array}{c}\text { ChemTica USA, Durant, } \\
\text { OK }\end{array}$ \\
\hline Eugenol & EUG & $\begin{array}{l}\text { 3-(3-Methoxy-4-hydroxyphenyl)prop-1- } \\
\text { ene }\end{array}$ & $100 \mathrm{mg}$, cotton roll & $\begin{array}{c}\text { Sigma-Aldrich, Milwaukee, } \\
\text { WI }\end{array}$ \\
\hline Isoeugenol & ISO & $\begin{array}{l}\text { 3-(3-Methoxy-4-hydroxyphenyl)prop-2- } \\
\text { ene }\end{array}$ & $100 \mathrm{mg}$, cotton roll & $\begin{array}{l}\text { Spectrum Chemical, } \\
\text { Gardena, CA }\end{array}$ \\
\hline \multirow[t]{2}{*}{ Methyl salicylate } & MS & Methyl 2-hydroxybenzoate & $100 \mathrm{mg}$, cotton roll & $\begin{array}{c}\text { Sigma-Aldrich, Milwaukee, } \\
\text { WI }\end{array}$ \\
\hline & MSCL & & $2 \mathrm{mg}$, commercial dispenser & $\begin{array}{l}\text { ChemTica USA, Durant, } \\
\text { OK }\end{array}$ \\
\hline \multirow[t]{2}{*}{ 2-Phenylethanol } & $\mathrm{PE}$ & 2-Phenylethanol & $100 \mathrm{mg}$, cotton roll & $\begin{array}{l}\text { Sigma-Aldrich, Milwaukee, } \\
\text { WI }\end{array}$ \\
\hline & PECL & & $2 \mathrm{mg}$, commercial dispenser & $\begin{array}{c}\text { ChemTica USA, Durant, } \\
\text { OK }\end{array}$ \\
\hline
\end{tabular}

when meaningful numbers of the flies were caught in particular tests. The tests were conducted in 0.5 to 1.5 -ha plots of spring wheat, corn, and soybean at the Eastern South Dakota Soil and Water Research Farm $\left(44^{\circ} 19^{\prime} \mathrm{N}, 96^{\circ} 46^{\prime} \mathrm{W}, 500-\mathrm{m}\right.$ elevation). Crops in the plots were grown using common agronomic practices, with no insecticide applied to plots from the planting through the sampling periods each year.

Yellow sticky traps (Pherocon AM, Trecé, Adair, OK) were used for the tests. Each trap was folded along its midline so that two faces of adhesive surface were exposed for capturing insects. The traps were deployed individually on 1-m tall stakes and set just above the canopy ( $\approx 0.7-\mathrm{m} \mathrm{ht}$.) in spring wheat and soybean plots and at the top of the stake in corn plots.

Traps were baited either with a cotton roll $(3.8 \mathrm{~cm}$ long; Patterson, St. Paul, MN) impregnated with $100 \mathrm{mg}$ of a volatile chemical or with a controlled-release, plastic sachet containing $2 \mathrm{mg}$ of chemical (2-phenylethanol or methyl salicylate). A chemical was applied to a cotton roll by pipette as either stock solution or with the camphor treatment after dissolution in ethanol. Ethanol was used as the control. Wicks were prepared in the morning and clipped on a nonadhesive face of traps in the field a few hours later. The traps were deployed 10- to 30-m apart in the plots for various 2-day periods. Individual baited traps served as replicates, and treatments of volatile chemicals were replicated four to 10 times depending on the number tested and plot size.

The traps were retrieved from plots at the end of each test and taken to the laboratory and stored in refrigerators, and nontarget flies on them were identified and counted within a few days. The flies were identified to genus or species, depending on the condition of specimens on the traps; sex of the specimens was determined for Anthomyiidae by their dimorphic compound eyes (females, dichoptic; males, holoptic) [9]. Counts of nontarget flies for each 2-day trap period were subjected to separate analyses of variance by species and, for Anthomyiidae, by sex, using a generalized linear mixed model (PROC GLIMMIX $[10,11])$. Treatment means were separated by the LSMEANS feature with TukeyKramer adjustment. Zero counts for the camphor treatment were omitted in order to support the robustness of parametric analyses in tests 1 and 2 [11]. 
TABLE 2: Tests of the attractancy of volatile chemicals to beneficial insects in agricultural plots near Brookings, SD.

\begin{tabular}{lcccc}
\hline Test & Crop & Date & Volatiles tested $^{1}$ & Flies evaluated \\
\hline 1 & Corn & Aug 2-4, 2004 & CAM, IMP, PE, TC, TERP, ETH & Homoneura bispina (Lauxaniidae); Olcella sp. (Chloropidae) \\
2 & Soybean & Aug 17-19,2004 & CAM, IMP, PE, TC, TERP, ETH & Olcella sp. \\
3 & Wheat & Jun 15-17, 2005 & PE, PECL, MS, MSCL, ETH & Male Delia spp. (Anthomyiidae) \\
4 & Corn & Jul 13-15, 2005 & IMP, MS, PE, ETH & H. bispina, Camptoprosopella borealis (Lauxaniidae) \\
5 & Corn & Jul 13-15, 2005 & PECL, MSCL, ETCL & H. bispina, C. borealis \\
6 & Soybean & Jul 14-16, 2005 & PE, PECL, MS, MSCL, ETH & Male Delia spp. \\
7 & Soybean & Jul 20-22, 2005 & 4AA, EUG, ISO, PE, ETH & Male and female Delia spp. \\
\hline
\end{tabular}

${ }^{1}$ See Table 1 for abbreviations.<smiles>OCCc1ccccc1</smiles>

Methyl salicylate<smiles>COC(=O)c1ccccc1O</smiles>

2-Isopropyl-3-methoxypyrazine<smiles>COc1nccnc1CC(C)O</smiles><smiles>C=CCc1cccc(OC)c1O</smiles><smiles>C=CCc1ccc(OC)c(OC)c1</smiles><smiles>CC1=CCC(C(C)(C)O)CC1</smiles>

Isoeugenol<smiles>C/C=C/c1ccc(O)c(OC)c1</smiles><smiles>C=C1CC/C=C(/C)CC[C@@H]2[C@@H]1CC2(C)C</smiles>

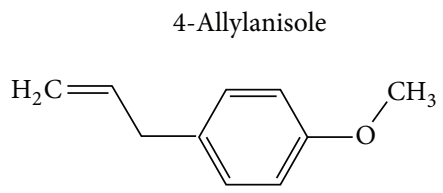

Figure 1: Chemical structures of test compounds.

\section{Results}

3.1. Overview. Significant numbers of flies from the families Lauxaniidae, Chloropidae, and Anthomyiidae were captured among the various tests. Trap counts of these flies often varied significantly among the volatile chemicals used to bait the traps. The results for each of these families are reported separately in the following.

3.2. Lauxaniidae. Trap catch of two species of lauxaniid flies, Homoneura bispina (Loew) and Camptoprosopella borealis Shewell, varied with volatile attractants in three tests in corn plots. In 2004 (test \#1), trap catch of H. bispina varied with volatile attractant $(F=94.63$; d.f. $=5,53$; and $P<0.0001)$. More $H$. bispina were caught on traps baited with 2phenylethanol compared with those baited with any other compound (Figure 2). Trap catch did not differ among the other volatile compounds, except that terpineol-baited traps had fewer $H$. bispina than ones baited with ethanol.

A follow-up test (\#4) in 2005 also showed that trap catch of $H$. bispina varied with volatile chemicals $(F=13.31$; d.f. $=3$, 36; and $P<0.0001)$. Results confirmed that 2-phenylethanol increased trap catch of $H$. bispina over other volatiles tested and showed that trap catches were higher on traps baited with methyl salicylate compared with those baited with ethanol or 2-isopropyl-3-methoxypyrazine (IMP) (Figure 3(a)). 


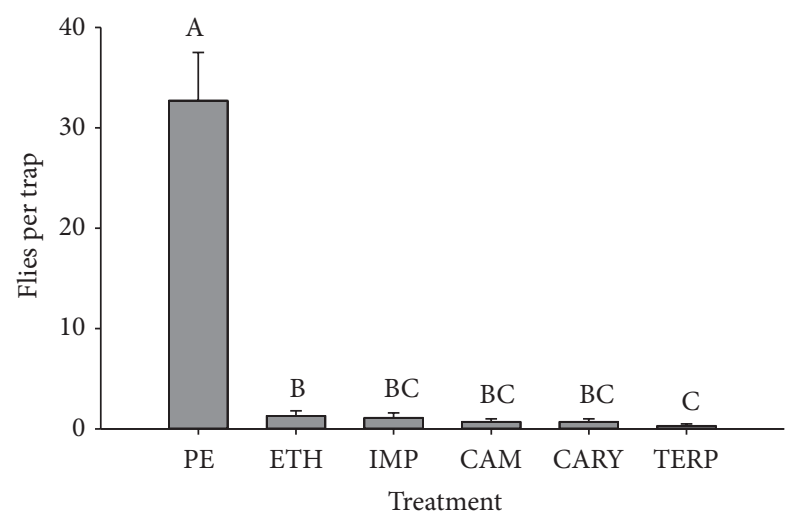

Figure 2: Mean number of adult Homoneura bispina per sticky trap $( \pm$ SE) baited with volatile chemical from Aug 2 to Aug 4, 2004, in a corn plot near Brookings, SD (test \#1). Bars without the same letter above have means that differ significantly. $\mathrm{PE}=$ 2-phenylethanol, ETH = ethanol (control), IMP = 2-isopropyl-3methoxypyrazine, CAM = camphor, CARY = trans-caryophyllene, and TERP $=$ terpineol, each at $100 \mathrm{mg}$ on a cotton roll. Homoneura bispina, corn, 2004.

Catch of H. bispina did not differ between ethanol and IMP.

In addition, trap catch of $C$. borealis differed among volatiles in test $\# 4(F=5.20$; d.f. $=3,36$; and $P=0.004)$. Traps baited with methyl salicylate caught more C. borealis than those baited with ethanol (Figure 3(b)). Catch of $C$. borealis on traps baited with 2-phenylethanol or IMP did not differ from that on traps baited with either methyl salicylate or ethanol, and trap catch did not differ between 2-phenylethanol and IMP.

Trap catch of H. bispina and C. borealis each varied among volatiles in a final test using controlled-release lures (test \#5). However, trap catch of lauxaniids was largely converse to that using cotton rolls as lures in test \#4. That is, traps baited with methyl salicylate caught more $H$. bispina than those baited with 2-phenylethanol or ethanol (Figure 4(a); $F=4.41$; d.f. $=2,12$; and $P=0.037$ ), whereas traps baited with 2 phenylethanol caught more $C$. borealis than those baited with methyl salicylate or ethanol (Figure 4(b); $F=5.16$; d.f. $=2,12$; and $P=0.024$ ).

3.3. Chloropidae. Counts of an Olcella sp. varied among attractants in corn and soybean plots in 2004 (corn, test \#1: $F=188.66$; d.f. $=4,44$; and $P<0.0001$; soybean, test $\# 2: F=73.42$; d.f. $=4,15$; and $P<0.0001$ ), as the counts were significantly more abundant on traps baited with IMP compared with traps baited with other volatile compounds. In corn, IMP-baited traps caught a mean $( \pm$ SE) of $103.4( \pm 12.6)$ Olcella flies per trap, whereas counts averaged $\leq 3.3$ Olcella flies per trap for each of the other treatments (Figure 5(a)). In soybean, IMP-baited traps caught a mean $( \pm \mathrm{SE})$ of 83.8 $( \pm 9.1)$ Olcella flies per trap, whereas counts averaged $\leq 2.0$ Olcella flies per trap for other treatments (Figure 5(b)). Traps baited with IMP and other attractants in 2005 (test \#3) did not capture sufficient numbers of Olcella flies for analysis.
3.4. Anthomyiidae. Trap catch of adult Delia spp. varied by volatile chemicals in three tests. In spring wheat (test \#3), catch of male Delia flies was greater on traps baited with 2phenylethanol on a cotton wick than with all other treatments (Figure 6(a); $F=27.47$; d.f. $=4,25$; and $P<0.001$ ). Traps baited with 2-phenylethanol or methyl salicylate dispersed from a controlled-release dispenser captured more male Delia flies than traps baited with ethanol or methyl salicylate dispensed from cotton rolls. Numbers of female Delia flies did not vary among attractants $(P=0.059)$.

In soybean (test \#6), the catch of male Delia flies was greater on traps baited with 2-phenylethanol on a cotton wick or in a controlled-release dispenser than on traps with other treatments (Figure 6(b); $F=6.84$; d.f. $=4,20$; and $P=0.001$ ). The numbers of male Delia flies did not differ among traps baited with a controlled-release lure of methyl salicylate or ones baited with cotton rolls imbued with ethanol or methyl salicylate. Trap catch of female Delia flies did not vary among volatile chemicals $(P=0.16)$.

In a second test in soybean (test \#7), the trap catch of both male $(F=17.25$; d.f. $=4,20$; and $P<0.001)$ and female Delia flies $(F=4.20$; d.f. $=4,20$; and $P=0.013)$ varied among volatile chemicals. More male and female Delia flies were captured on traps baited with 2-phenylethanol than on those baited with other volatile chemicals (Figure 7); trap catch of Delia spp. did not vary among eugenol, isoeugenol, 4-allylanisole, or ethanol.

\section{Discussion}

Some of the findings in this study represent novel reports of attractancy for particular volatile compounds to the two lauxaniid species, Homoneura bispina and Camptoprosopella borealis, and to the chloropid flies in the genus Olcella. However, previous reports have documented responses of Delia flies to traps baited with volatile attractants such as 2phenylethanol [12]. Results of this study are compared below with findings of other studies for each group of flies.

4.1. Lauxaniidae. The attractancy of 2-phenylethanol and methyl salicylate to lauxaniids is novel, but the basis for their attraction is unclear. Consideration of lauxaniid biology and the natural occurrence of 2-phenylethanol and methyl salicylate may allow for inference about the basis of attraction for these two volatiles. Specific knowledge about the biology of $H$. bispina and C. borealis is lacking. Adult lauxaniids generally feed on fungi [13] and visit flowers [14], and larvae are typically saprophagous among fallen leaves, straw, rotting wood, and bird nests [15]. With regard to the chemicals, 2-phenylethanol is a compound associated with decaying vegetation [16], and methyl salicylate is induced in plants by herbivory to act as a volatile attractant of herbivore natural enemies [17]. However, 2-phenylethanol and methyl salicylate are also floral volatiles that attract pollinators [17, 18]. Thus, given the biology of lauxaniids, the increased trap catch of H. bispina and C. borealis to 2-phenylethanol and methyl salicylate may reflect an attraction to these compounds as floral attractants or as decaying vegetation that 


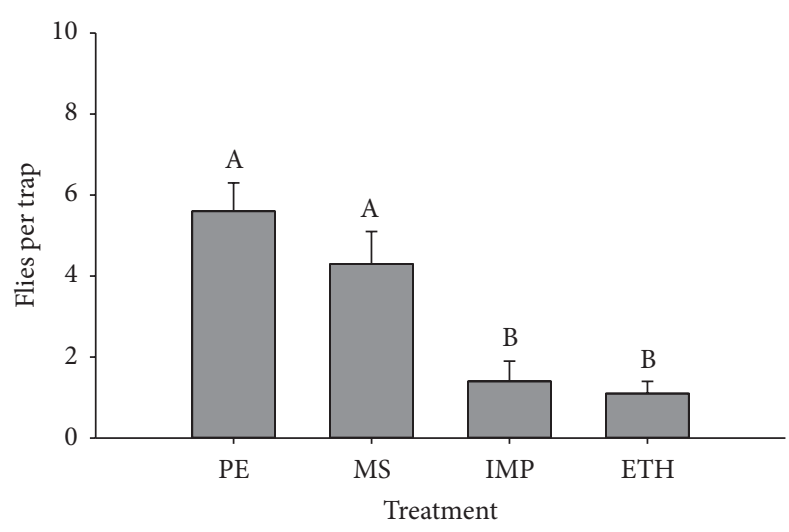

(a) Homoneura bispina, corn, 2005

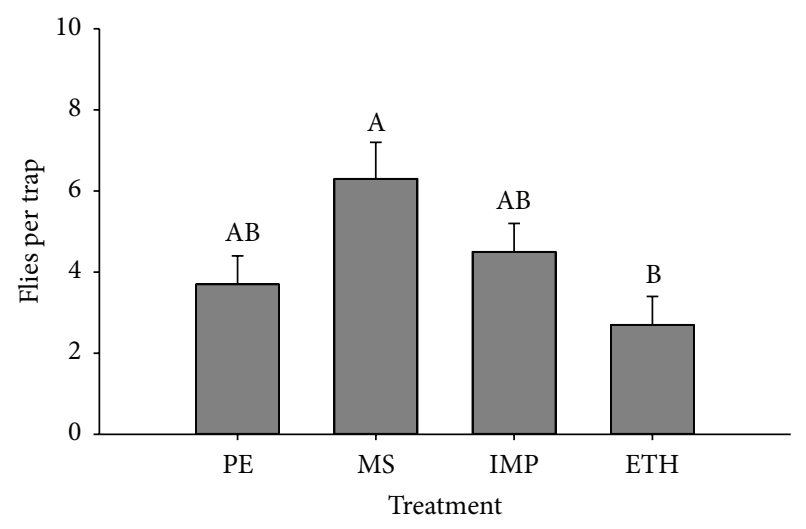

(b) Camptoprosopella borealis, corn, 2005

FIGURE 3: Mean number of lauxaniid flies per sticky trap ( \pm SE) baited with volatile chemicals from Jul 13 to Jul 15, 2005, in a corn plot near Brookings, SD (test \#4). For each species, bars without the same letters above them indicate that the means differ significantly. PE $=$ 2-phenylethanol, MS = methyl salicylate, IMP = 2-isopropyl-3-methoxypyrazine, and ETH = ethanol (control), each at $100 \mathrm{mg}$ on a cotton roll. (a) Adult Homoneura bispina; (b) adult Camptoprosopella borealis.

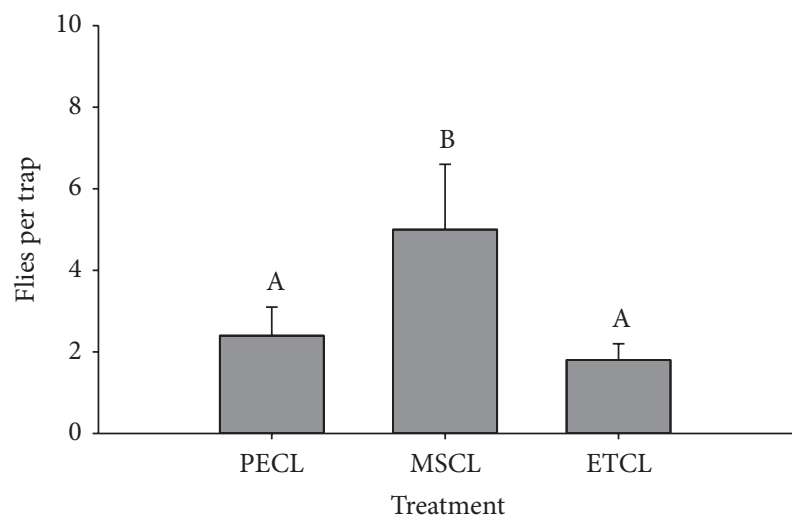

(a) Homoneura bispina, corn, 2005

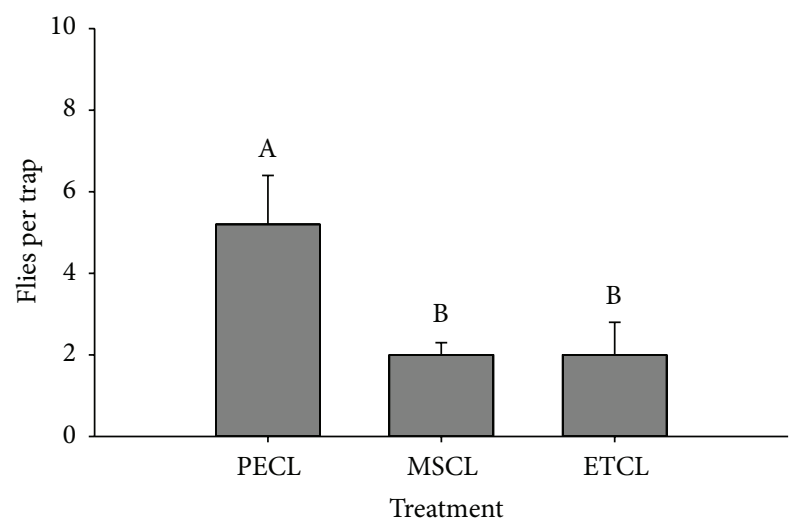

(b) Camptoprosopella borealis, corn, 2005

FIGURE 4: Number of lauxaniid flies per sticky trap $( \pm$ SE) baited with $2 \mathrm{mg}$ in controlled-release dispensers of ethanol (control) = ETCL, methyl salicylate = MSCL, or 2-phenylethanol = PECL in corn plots near Brookings, SD, Jul 13-15, 2005 (test \#5). (a) Adult Homoneura bispina; (b) adult Camptoprosopella borealis. For each species, bars without the same letter above them indicate that the means differ significantly.

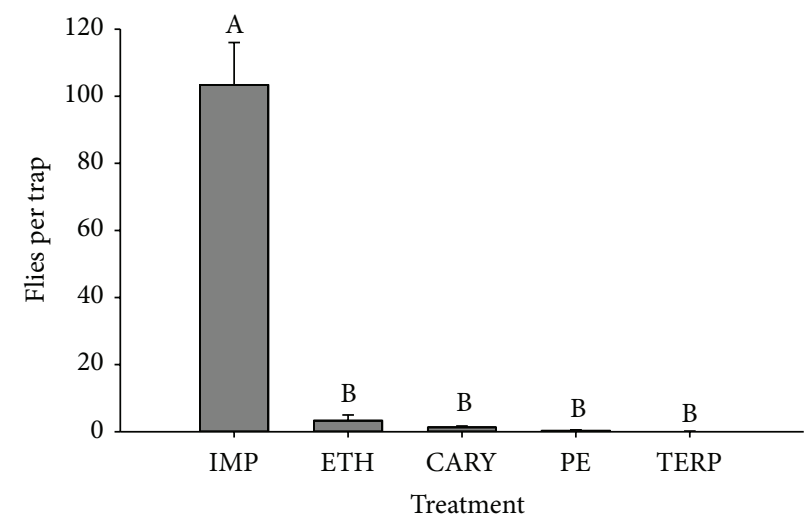

(a) Olcella flies, corn, 2004

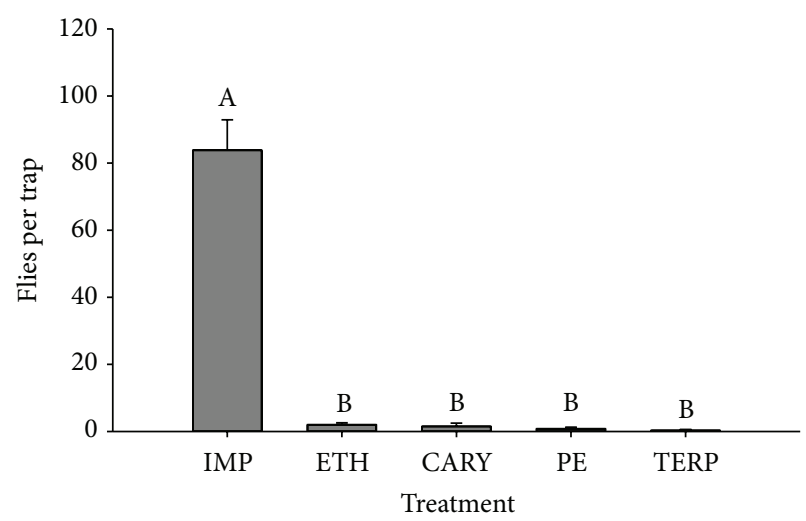

(b) Olcella flies, soybean, 2004

FIGURE 5: Mean number of adult Olcella sp. flies per sticky trap ( \pm SE) baited with $100 \mathrm{mg}$ of volatile chemicals in plots near Brookings, $\mathrm{SD}$. Chemicals dispensed on cotton rolls. Bars without the same letters above them indicate that the means differ significantly. (a) Aug 2-4, 2004, corn plot (test \#1). (b) Aug 17-19, 2004, soybean (test \#2). IMP = 2-isopropyl-3-methoxypyrazine, ETH = ethanol (control), CARY = trans-caryophyllene, $\mathrm{PE}=2$-phenylethanol, and TERP $=$ terpineol. Zero counts for camphor (CAM) traps not included. 


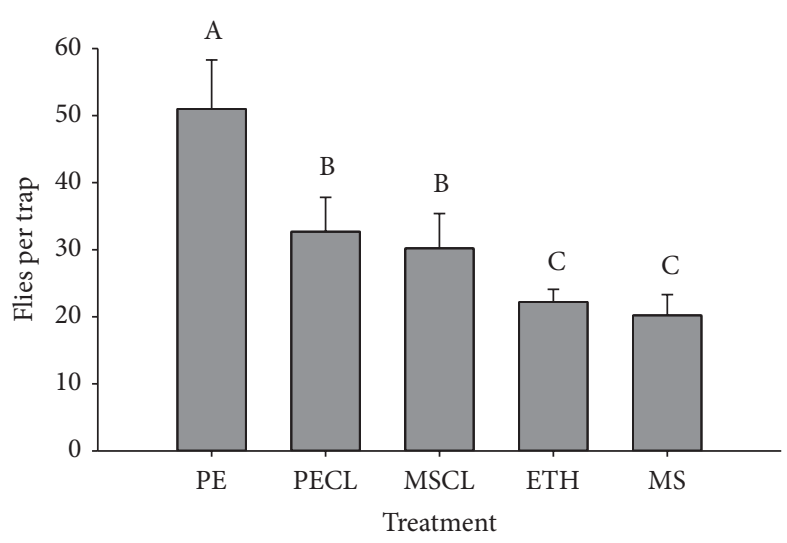

(a) đ̛ơ Delia flies, spring wheat, 2005

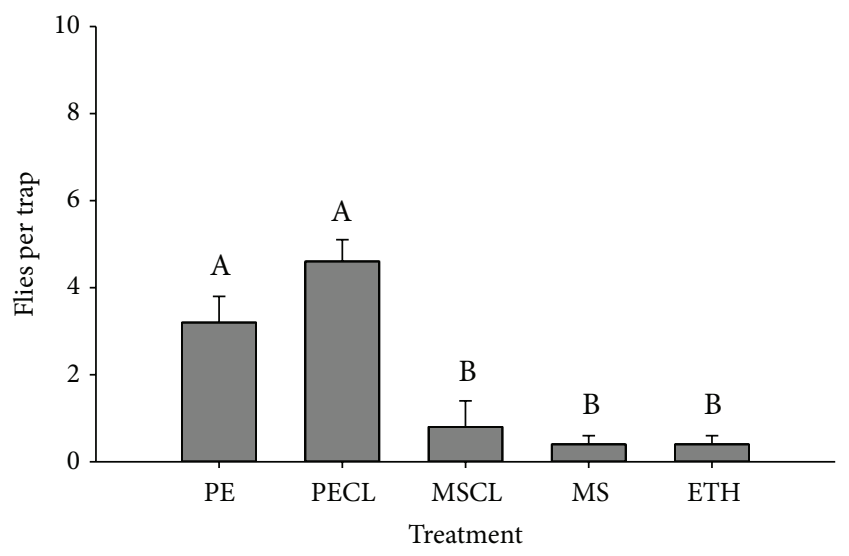

(b) ơơ Delia flies, soybean, 2005

Figure 6: Mean number $( \pm$ SE) of male Delia flies captured near Brookings, SD, on sticky traps baited with a volatile attractant. (a) Spring wheat, Jun 15-17, 2005 (test \#3). (b) soybean, Jul 14-16, 2005 (test \#6). PE = 2-phenylethanol, MS = methyl salicylate, and ETH = ethanol (control), each at $100 \mathrm{mg}$ on a cotton roll; PECL $=2$-phenylethanol and MSCL $=$ methyl salicylate, each at 2 mg on a controlled-release lure. For each graph, bars without the same letter above them indicate significant differences between means.

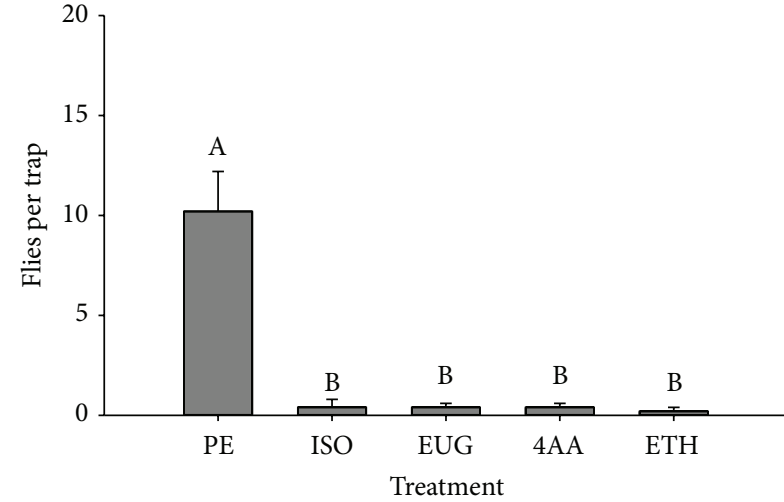

(a) ổ Delia flies, soybean, 2005

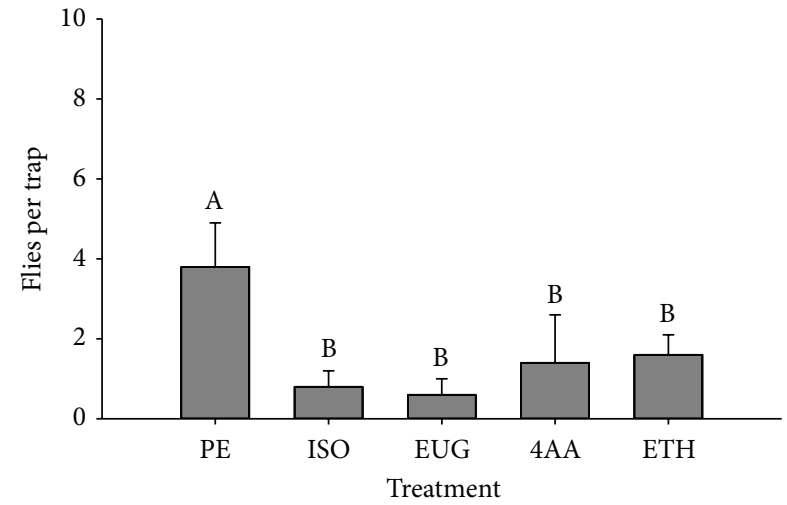

(b) 우 Delia flies, soybean, 2005

Figure 7: Mean number ( \pm SE) of male (a) and female (b) Delia flies captured on sticky traps baited with volatile chemical, Jul 20-22, 2005, in a soybean plot near Brookings, SD (test \#7). For each sex, bars without the same letters above them indicate that the means differ significantly. $\mathrm{PE}=$ 2-phenylethanol, EUG = eugenol; ISO = isoeugenol; 4AA = 4-allylanisole, and ETH = ethanol (control), each at $100 \mathrm{mg}$ on a cotton roll.

may indicate suitable larval habitat to ovipositing females. The differential responses of the two species to these compounds emanating from either cotton rolls or controlledrelease septa indicate that concentration and release rate influence lauxaniid response. Both cotton and plastic have been used effectively in studies with volatile attractants and flies; however, dispenser type may be a factor affecting trap catch, as different dispensers release volatile compounds at different rates $[19,20]$. Further study is needed to clarify these relationships.

4.2. Olcella Flies. The results of my study constitute the first report of attractancy of 2-isopropyl-3-methoxypyrazine (IMP) to Olcella sp. (and other insects). It significantly attracted large numbers of Olcella sp. in two tests in August 2004 but failed to catch meaningful numbers of Olcella sp. in a July 2005 test. The phenology of Olcella flies is not known for field crops in South Dakota. However, as sampling of insects directly relates to their abundance and activity, and trap catch can reflect the temporal dynamics of insects [21,22], I hypothesize that the disparity in trap catch between years may have been due to differences in abundance or activity of Olcella flies at the respective times of year (July versus August) when the tests were run. I suggest future tests across a broader time frame to determine the temporal dynamics involved in attraction of Olcella flies to IMP.

The basis of attractancy of IMP to Olcella sp. is unclear. IMP is a pungent volatile and structural analog of methoxyalkylpyrazines (MAP), which are defensive compounds of aposematic insects [23, 24]. As such, IMP was originally intended as a repellent control in screening volatile compounds for natural enemy responsiveness, when its unexpected attractancy to Olcella was discovered. Other studies have shown that Olcella spp. are attracted to various volatile compounds [6, 25-27]. For instance, Olcella trigramma (Loew) is attracted to hexyl butyrate and (E)-2-hexenyl 
butyrate, defensive compounds in the metathoracic scent glands of stink bugs (Hemiptera: Pentatomidae) [27] that seep out upon death [28]. Furthermore, chloropid flies are attracted to stink bugs and other true bugs (Hemiptera) that emit defensive secretions when being trapped in spider webs [29], and Zhang and Aldrich [27] have suggested that these defensive compounds function as kairomones to scavenging flies. Accordingly, I hypothesize that the increased trap catch of Olcella flies in my study was due to analogous attraction of these flies to IMP as a defensive secretion and suggest further testing of IMP and other MAPs for their attractancy to chloropids.

Alternatively, however, if Olcella flies are attracted to defensive compounds of trapped insects (e.g., in spider webs [27]), their attraction to IMP-baited traps could have ultimately been influenced by the capture of other insects on those traps. However, capture of other insects was not appreciable on IMP-baited traps in the present study. Thus, the capture of high numbers of Olcella flies was likely due to their direct attraction to IMP.

4.3. Delia Flies. Previous reports have shown attractancy of 2-phenylethanol to Delia spp., and male Delia are particularly responsive to this compound [12, 16, 30]. 2-Phenylethanol was shown to be a key component of decomposing onion pulp that attracted onion flies $[D .(=$ Hylemya) antiqua (Meigen)] and seedcorn maggot flies [D. (=Hylemya) platura (Meigen)]. Correspondingly, attraction of Delia spp. to 2-phenylethanol has been documented in onion $[12,16,30]$ but also in snap bean fields [12]. However, my study is the first known to document a trapping response of Delia spp. to 2-phenylethanol in wheat and soybean fields. Some species, such as D. platura and $D$. florilega (Zetterstedt) (bean seed maggot), are pests of seedling soybean [31], especially in fields where ovipositing females are attracted to soil that has had manure applied or green plant material incorporated [32]. Traps baited with attractants such as 2-phenylethanol might be useful as a monitoring tool to assess Delia populations in soybean fields [12]. However, tests may be needed to determine how the presence of competing volatiles associated with manure and decaying green plant material might affect the catch of traps baited with synthetic volatile attractants.

\section{Conclusions}

In summary, three types of flies were caught serendipitously in this study on yellow sticky traps that had been baited with a relatively limited range of attractants and placed in a limited number of field-crop habitats at a single location in eastern South Dakota. As such, there is a rich set of follow-up questions that may be pursued systematically in future studies at various geographic locations. These studies may include tests of chemical analogs and varied dosages of the volatiles used here in order to determine structureactivity relationships and sensitivity involved in the flies' attraction. Future studies may be conducted to determine if response varies by sex and reproductive status, particularly for lauxaniids and Olcella flies. In addition, future studies may also test attractancy among dispensers with different release rates [19] and across different trap designs, including traps ones that leave flies intact upon removal and thereby facilitate researchers' ability to readily identify flies to species. Finally, additional studies on the basic biology of $H$. bispina, C. borealis, and Olcella flies are needed to make inferences about the bases for responses to volatile chemicals. The suggested studies are likely to greatly expand knowledge about the chemical ecology of these groups of flies.

\section{Disclosure}

The paper reports research results only. Mention of a trademark or proprietary product does not constitute a guarantee or warranty of the product by USDA and does not imply its approval to the exclusion of other products that may also be suitable.

\section{Competing Interests}

The author declares that there are no competing interests regarding the publication of this paper.

\section{Authors' Contributions}

Eric Beckendorf, David Mills, Kendra Jensen, Hanna Fetzer, Joshua Pedro, and Ryan Rubbelke provided technical assistance. Stephen Gaimari and Jon Kieckhefer identified flies. Mark West advised on statistical analysis. Sharon Papiernik and Fathi Halaweish provided advice on drawing chemical structures. Jan Menely, Michael Catangui, and Leslie Hammack advised on attractants. Eric Beckendorf, Lauren Hesler, Deirdre Prischmann-Voldseth, Leslie Hammack, and Sharon Papiernik graciously reviewed drafts of this paper.

\section{References}

[1] R. W. Matthews and J. R. Matthews, Insect Behavior, Springer, 2009.

[2] C. M. Allen, S. Erdelez, and M. Marinov, "Looking for opportunistic discovery of information in recent biomedical research-a content analysis," Proceedings of the Association for Information Science and Technology, vol. 50, no. 1, pp. 1-11, 2013.

[3] S. Buchholz, M. Kreuels, A. Kronshage, H. Terlutter, and O.D. Finch, "Bycatches of ecological field studies: bothersome or valuable?" Methods in Ecology and Evolution, vol. 2, no. 1, pp. 99-102, 2011.

[4] L. R. Spears and R. A. Ramirez, "Learning to love leftovers using by-catch to expand our knowledge in entomology," American Entomologist, vol. 61, no. 3, pp. 168-173, 2015.

[5] L. Hammack and L. S. Hesler, "Phenylpropanoids as attractants for adult Stomoxys calcitrans (Diptera: Muscidae)," Journal of Medical Entomology, vol. 33, no. 5, pp. 859-862, 1996.

[6] B. E. Hibbard, D. K. Jewett, and L. B. Bjostad, "Pentanoic acid attracts Olcella parva (Adams) (Diptera: Chloropidae) in Colorado corn fields," Journal of the Kansas Entomological Society, vol. 70, no. 1, pp. 67-69, 1997. 
[7] R. V. Dowell, "Attraction of non-target insects to three male fruit fly lures in California," Pan-Pacific Entomologist, vol. 91, no. 1, pp. 1-19, 2015.

[8] L. S. Hesler, "Volatile semiochemicals increase trap catch of green lacewings (Neuroptera: Chrysopidae) and flower flies (Diptera: Syrphidae) in corn and soybean plots," Journal of Insect Science, vol. 16, no. 1, pp. 1-8, 2016.

[9] J. Savage, A.-M. Fortier, F. Fournier, and V. Bellavance, "Identification of Delia pest species (Diptera: Anthomyiidae) in cultivated crucifers and other vegetable crops in Canada," Canadian Journal of Arthropod Identification, no. 29, pp. 1-40, 2016.

[10] SAS Institute, SAS 9.3 Procedures Guide: Statistical Procedures, SAS Institute, Cary, NC, USA, 2012.

[11] J. D. Reeve and B. L. Strom, "Statistical problems encountered in trapping studies of scolytids and associated insects," Journal of Chemical Ecology, vol. 30, no. 8, pp. 1575-1590, 2004.

[12] T. P. Kuhar, W. D. Hutchison, J. Whalen et al., "Field evaluation of a novel lure for trapping seedcorn maggot adults," Plant Health Progress, 2006.

[13] E. C. Broadhead, "Adaptations for fungal grazing in Lauxaniid flies," Journal of Natural History, vol. 18, no. 4, pp. 639-649, 1984.

[14] P. G. Kevan and H. G. Baker, "Insects as flower visitors and pollinators," Annual Review of Entomology, vol. 28, no. 1, pp. 407-453, 1983.

[15] R. M. Miller and B. A. Foote, "Biology and immature stages of eight species of Lauxaniidae (Diptera). II. Descriptions of immature stages and discussion of larval feeding habits and morphology," Proceedings of the Entomololgical Society of Washington, vol. 78, no. 1, pp. 16-37, 1976.

[16] Y. Ishikawa, T. Ikeshoji, Y. Matsumoto, M. Tsutsumi, and Y. Mitsui, "2-Phenylethanol: an attractant for the onion and seed-corn flies, Hylemya antiqua and $H$. platura (Diptera: Anthomyiidae)," Applied Entomology and Zoology, vol. 18, no. 2, pp. 270-277, 1983.

[17] A. Das, S.-H. Lee, T. K. Hyun, S.-W. Kim, and J.-Y. Kim, "Plant volatiles as method of communication," Plant Biotechnology Reports, vol. 7, no. 1, pp. 9-26, 2013.

[18] J. T. Knudsen, L. Tollsten, and L. G. Bergström, "Floral scentsa checklist of volatile compounds isolated by head-space techniques," Phytochemistry, vol. 33, no. 2, pp. 253-280, 1993.

[19] P. S. Baker, J. Hendrichs, and P. Lledo, "Improvement of attractant dispensing systems for the mediterranean fruit fly (Diptera: Tephritidae) sterile release program in Chiapas, Mexico," Journal of Economic Entomology, vol. 81, no. 4, pp. 1068$1072,1988$.

[20] T. E. Shelly, "Detection of male Mediterranean fruit flies (Diptera: Tephritidae): performance of trimedlure relative to capilure and enriched ginger root oil," Proceedings of the Hawaiian Entomolgical Society, vol. 45, pp. 1-7, 2013.

[21] T. R. E. Southwood and P. A. Henderson, Ecological Methods, Blackwell Science, Oxford, UK, 3rd edition, 2000.

[22] L. W. Cohnstaedt, K. Rochon, A. J. Duehl et al., "Arthropod surveillance programs: basic components, strategies, and analysis," Annals of the Entomological Society of America, vol. 105, no. 2, pp. 135-149, 2012.

[23] B. P. Moore, W. V. Brown, and M. Rothschild, "Methylalkylpyrazines in aposematic insects, their hostplants and mimics," Chemoecology, vol. 1, no. 2, pp. 43-51, 1990.

[24] A. G. King and J. Meinwald, "Review of the defensive chemistry of coccinellids," Chemical Reviews, vol. 96, no. 3, pp. 1105-1122, 1996.
[25] O. K. Jantz and M. Beroza, "Caproic acid as an attractant for Olcella parva," Journal of Economic Entomology, vol. 60, no. 1, pp. 290-291, 1967.

[26] M. Boppre and B. R. Pitkin, "Attraction of Chloropid flies to pyrrolizidine alkaloids (Diptera: Chloropidae)," Entomologia Generalis, vol. 13, no. 1, pp. 81-85, 1988.

[27] Q.-H. Zhang and J. R. Aldrich, "Attraction of scavenging chloropid and milichiid flies (Diptera) to metathoracic scent gland compounds of plant bugs (Heteroptera: Miridae)," Environmental Entomology, vol. 33, no. 1, pp. 12-20, 2004.

[28] J. G. Aldrich, J. E. Oliver, W. R. Lusby, J. P. Kochansky, and J. A. Lockwood, "Pheromone strains of the cosmopolitan pest, Nezara viridula (Heteroptera: Pentatomidae)," Journal of Experimental Zoology, vol. 244, no. 1, pp. 171-176, 1987.

[29] T. Eisner, M. Eisner, and M. Deyrup, "Chemical attraction of kleptoparasitic flies to heteropteran insects caught by orbweaving spiders," Proceedings of the National Academy of Sciences of the United States of America, vol. 88, no. 18, pp. 81948197, 1991.

[30] Y. Ishikawa, Y. Matsumoto, M. Tsutsumi, and Y. Mitsui, "Mixture of 2-phenylethanol and n-valeric acid, a new attractant for the onion and seed-corn flies, Hylemya antiqua and H. platura (Diptera: Anthomyiidae)," Applied Entomology and Zoology, vol. 19, no. 4, pp. 448-455, 1984.

[31] L. G. Higley and R. B. Hammond, "Seedcorn maggot," in Handbook of Soybean Insect Pests, L. G. Higley and D. J. Boethel, Eds., pp. 77-79, Entomological Society of America, Annapolis, Md, USA, 1994.

[32] R. B. Hammond, "Influence of cover crops and tillage on seedcorn maggot (Diptera: Anthomyiidae) populations in soybeans," Environmental Entomology, vol. 19, no. 3, pp. 510-514, 1990. 

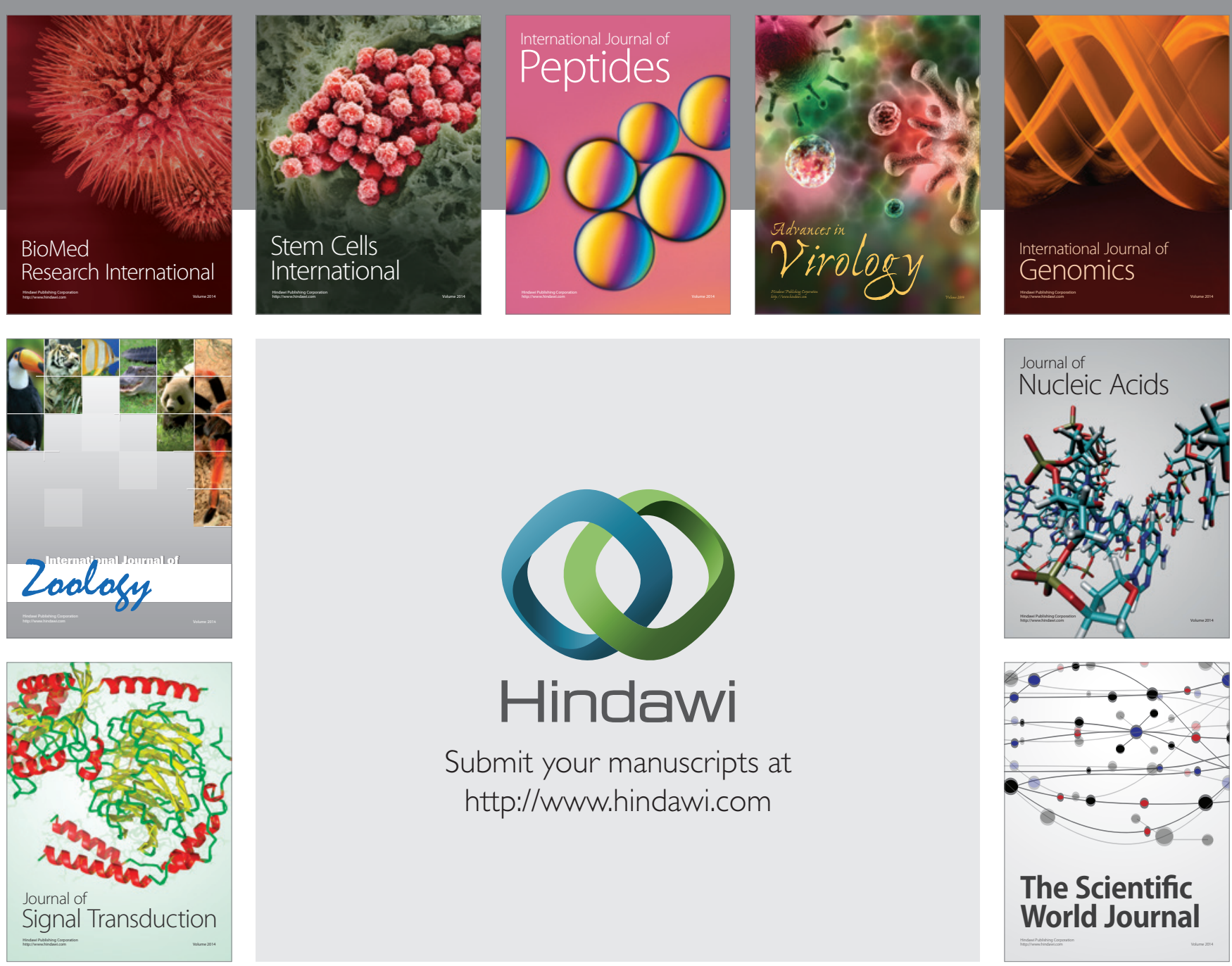

Submit your manuscripts at

http://www.hindawi.com
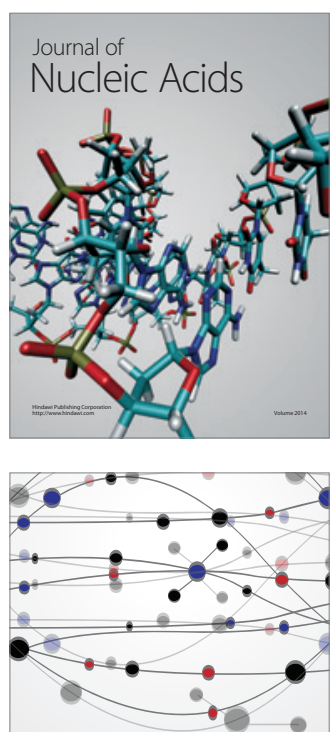

The Scientific World Journal
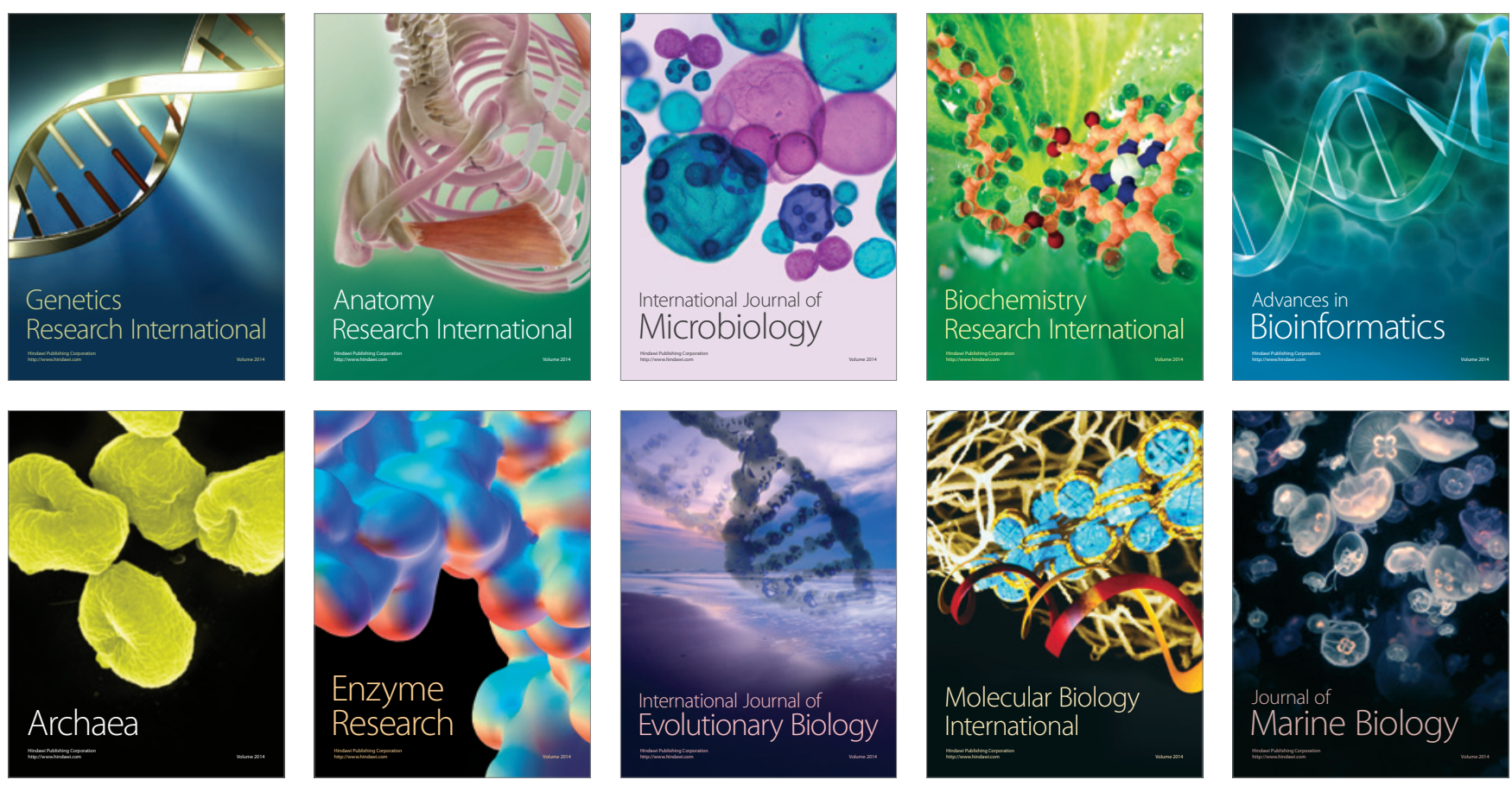